\title{
Assessment of the Effects of Community Expansion and Land Use Transformation on a Coastal Area in Thailand
}

\author{
Siriluk Prukpitikul, Payatipol Narangjavana, and Ruangrai Tokrisna
}

\begin{abstract}
This study investigates land use change over the past 12 years at Chao Samram beach, Thailand, and evaluates the physical, social, and economic impact on the area. From 1999 to 2011, land use changed significantly, especially in the urban, aquaculture and salt flat, and bare land areas. Conversely, we observe that the area covered by mangrove forests and water did not decrease significantly. Only the area used for agriculture and rice farming decreased. We also note that the density distribution of communities along the coast was according to the economic and social development plan of the municipal district, and population density has increased continuously since 2004. Economic activity revolves around two sectors: rice farming accounts for $59.29 \%$ of total income and tourism, 36.6\%. An investigation of the physical landscape indicates that the beach eroded severely during 2005-2006 and 2009-2010 and finds evidence of accretion in 2004-2005 and 2008-2009. The total economic loss that occurred because of the threatened land and buildings is approximately $\mathbf{1 7 7 . 6 9}$ million baht. This study concludes that to understand coastal zone development, we need to consider the long-term physical, social, and economic losses.
\end{abstract}

Index Terms-Coastal communities, transformation of land use, coastal area change.

\section{INTRODUCTION}

The coastal zone is an area of social, economic, and ecological significance. Beach areas have substantive resources, and they are an ecosystem that is sensitive to changes that occur either naturally or from human activities. The Office of Natural Resources and Environment Policy and Planning [1] stated that many coastal areas in Thailand are now vulnerable to erosion owing to economic expansion. It has been reported that severe erosion has occurred along the coastline at an average rate of $5 \mathrm{~m} / \mathrm{yr}$ [2], [3]. The Food and Agriculture Organization of the United Nations (FAO) [4] reported in 2007 that erosion becomes worse whenever applied countermeasures are inappropriate and if the effects on adjacent shores are not carefully evaluated. Moreover, the tourism industry, a mainstay of the economy in many coastal communities, has a considerable effect on erosion rates. Kleppel [5] showed that $95 \%$ of land use decisions are made at the local level. The impact of land use change and exploitation of the coastal zone could be factors contributing to coastal zone changes [6]-[9].

Manuscript received May 15, 2015; revised September 1, 2015.

The authors are with the Graduate School, Kasetsart University-Sustainable Land Use and Natural Resource Management Center (KU-SLUSE), Kasetsart University, 50 Ngam Wong Wan Rd, Ladyaow, Chatuchak, Bangkok, Thailand (e-mail: siriluk2000@yahoo.com).
Chao Samram beach in Petchaburi Province was selected as the site for this study. This beach is a coastal wetland that slopes slightly to the east of the Gulf of Thailand. It is a white sandy beach with a quiet and cool atmosphere. It has an abundance of marine shells, hermit crabs, and jellyfish. This beach is a tourist attraction with hotel accommodations. Therefore, it is experiencing rapid economic growth. Based on a strategic plan for development, land use changes in the area were slated to proceed at various spatial levels and within various time periods. Over the past 10 years, coastal erosion has been one of the major environmental problems at this beach, occurring at a rate of approximately 3-4 m/yr [2], [3]. Thus, land utilization could be a factor contributing to changes to the coastal zone. On the other hand, the erosion problem may have caused socio-economic impacts in this area. Hence, this study focuses on 1) examining the land use changes over the past 12 years in the coastal area of Chao Samram beach, and 2) evaluating the physical, social, and economic impact of changes to coastal land use in the area. It is hoped that this study will provide a better understanding of the sustainable, long-term development of coastal zones.

\section{METHOD}

The geographic area of study encompasses about $7 \mathrm{~km}$ of Chao Samran beach and $4 \mathrm{~km}$ of the adjacent beaches in Petchaburi Province, as displayed in Fig. 1. Chao Samran beach is located within the Hat Chao Samran municipal district, which has a total area of $19,445 \mathrm{~km}^{2}$ and consists of seven villages with a total population of approximately 4,500 people [10]. The materials used in this study consist of LANDSAT images of 1999-2011, a THAICHOTE image from 2012, Differential Global Positioning System (DGPS), GPS, digital camera, eCognition Developer 64, and ArcGIS software. The overall methodology flow chart is shown in Fig. 2.

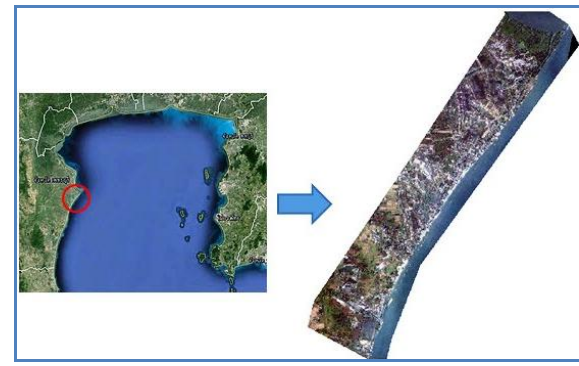

Fig. 1. The study area, located along Chao Samran beach, Petchaburi Province, Thailand.

\section{A. Land use Change and the Growth of the Community}

LANDSAT images were studied to ascertain the changes in 
land use and the growth of the community over the last 12 years. The rectified LANDSAT images obtained during 1999-2011 were processed using image segmentation and classification. The image classification process involved creating a rule set, classifying thresholds, supervising classification, post-classification work, and mapping. The images were classified into five land use types: 1) mangroves, 2) aquaculture and salt flats, 3) agriculture and rice fields, 4) bare land, and 5) urban and building area. The classified images were checked for accuracy by a ground truth survey, and the classified maps were then analyzed using a post-classification technique. The expansion of the community was evident from the development of the urban area, a fact corroborated by the growth of income and population. We performed this assessment by viewing a time series of THAICHOTE images at a 2-m resolution ordinarily utilized for land use detection. The statistical analysis was carried out using data collected from the Petchaburi Provincial Statistical Office Report [10] and the Hat Chao Samran municipal district [11].

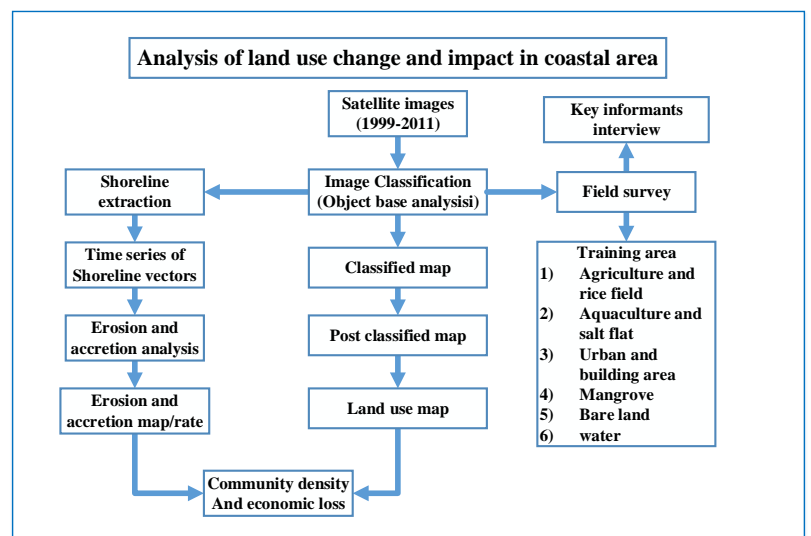

Fig. 2. The overall methodology flow chart of land use change and impact analysis in coastal area.

\section{B. Analysis of Impact to the Coastal Area}

Changes to the coastal area were analysed using remote sensing and spatial techniques. The eCognition Developer 64 software provided the object-based analysis techniques to rectify satellite images and extract a time series of the shoreline vectors. LANDSAT satellite images at 30-m resolution taken from 1999 to 2011 were selected as the input data. The erosion and accretion areas were determined by processing a time series of shoreline vectors and by using the union and intersect techniques provided by the Arc Toolbox in ArcGIS. The accuracy of shoreline mapping is based on the tide-coordinated shoreline [12]. Thus, the effect of tides needs to be included. Finally, using the Digital Shoreline Analysis System (DSAS), a baseline measurement method was introduced to calculate the erosion and accretion rates from a time series of shoreline images [13].

\section{Assessment of Economic Loss}

We arrived at an assessment of economic losses by measuring economic vulnerability as defined by the Intergovernmental Panel on Climate Change (IPCC) in 1997 cited in [14], and we utilized the appraisal of land prices in the area performed by the Department of Marine and Coastal Resources [2] using the market comparison approach.
Economic vulnerability $(E V)$ is computed from a) the value of threatened buildings and structure $(T V B S)$ and $\mathrm{b}$ ) the value of threatened lands in the risk area $(T V L)$.

$$
\begin{gathered}
E V=T V B S+T V L \\
T V B S=\sum_{i=1}^{n} V B i+\sum_{j=1}^{m} V S j
\end{gathered}
$$

where

$V B=$ value of building $\mathrm{i} ; \mathrm{n}$ is the total number of buildings at risk.

$V S=$ value of structure $\mathrm{j} ; \mathrm{m}$ is the total number of structures at risk.

$T V L=$ Land market value per $\mathrm{m}^{2} *$ total land area at risk (3)

To ascertain the value of the threatened lands (TVL) by shoreline retreat, we computed current market prices by averaging the prices quotes offered by real estate brokers cited in [15], [16]. The market value was estimated from the current land price per square meter. The data for property values (buildings and infrastructure) was collected from the Department of the Treasury, Thailand cited in [17]. In principle, the property value in this study equals the price of a comparable piece of property sold at around the same time. The collected data came from an area located approximately 150 meters inward from the base of the eroded coastline. The threatened lands were determined from LANDSAT images gathered in 1999-2011. The threatened buildings and structures were counted, and their size was calculated using these satellite images and those of the THAICHOTE Satellite in 2012 at a $2 \mathrm{~m}$ resolution. In addition, key informants in the area were interviewed as a means of surveying the threatened properties.

\section{RESULTS AND DISCUSSION}

\section{A. Land use Change along the Coast}

LANDSAT satellite images from 1999 to 2011 were processed for land use investigation. Land usage types were classified into five categories: 1) mangroves, 2) aquaculture and salt flats, 3) agriculture and rice fields, 4) bare land, and 5) urban and building area. From 1999 to 2011, changes in land use increased significantly, especially in the urban areas $(6.04 \%$ to $9.37 \%)$ and the aquaculture and salt flat area $(11.10 \%$ to $15.28 \%)$. On the other hand, the areas of mangrove forest $(5.59 \%$ to $6.49 \%)$, water $(0.26 \%$ to $0.37 \%)$ and bare land $(25.73 \%$ to $25.77 \%)$ changed very little or remained constant over the same period. Only the area used for agriculture and rice cultivation decreased from $51.27 \%$ to $42.71 \%$. A comparison of land use change for the entire area is represented in Fig. 3.

\section{B. The Growth of the Community along the Coastal Area}

The residents of Chao Samran beach work in the following sectors: 1) agriculture and aquaculture (farming and fishing), 2) industrial, 3) commercial, 4) services, and 5) tourism cited in [14]. According to data compiled from the Petchaburi Provincial Statistical Office [10] and from the strategic development plan offered by the Hat Chao Samran municipal district in the same year [11], the total income of the district 
amounted to 36.6 million baht, which represents an income per capita of approximately 20,824 baht. Tourism is a principal source of revenue with 33,600 tourists visiting the area per year, generating $13,440,000$ baht in revenue. Nevertheless, agriculture is the main source of income. Rice faming represents $59.29 \%$ of total income, and while tourism only accounts for $36.6 \%$ of income, annual revenue from this source is increasing, as shown in Fig. 4 and Fig. 5. Images from LANDSAT in 1999 to 2011 show a continuous increase in the density of communities along the coast, as shown in Fig. 4 and Fig. 5.

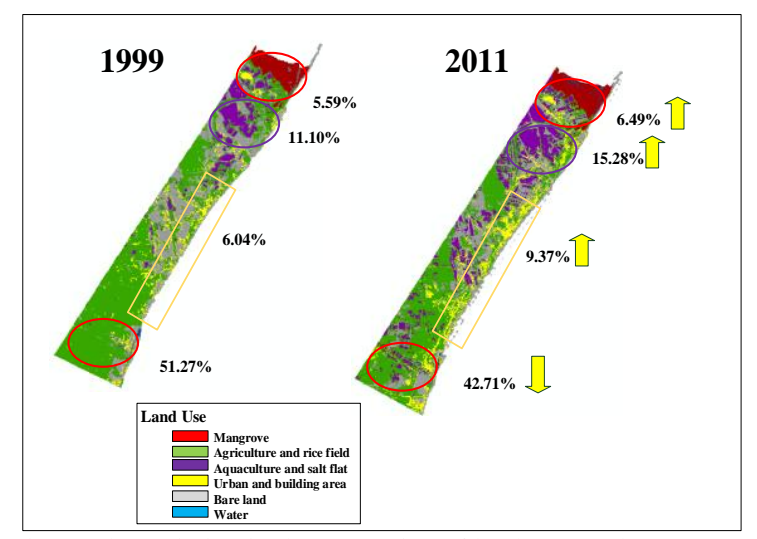

Fig. 3. The variation in the proportion of land use at Chao Samran beach,1999-2011. Land use is sorted in descending order: agriculture and rice field, aquaculture and salt flat, urban and building area, and mangrove.

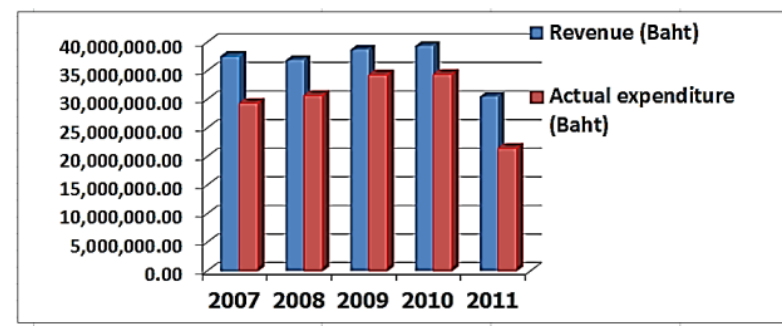

Fig. 4. Yearly revenue and expenditure for Hat Chao Samran municipality [11].

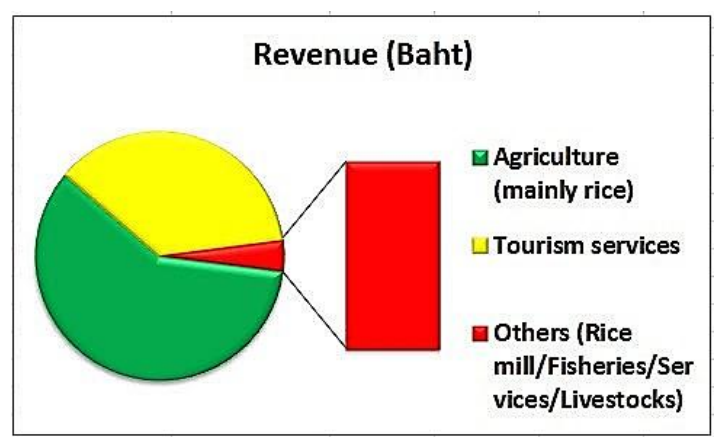

Fig. 5. Sources of revenue of Chao Samran municipal district during 2007-2011 [11].

Patterns of land use change, as determined from LANDSAT images in Fig. 6, show that the distribution of the communities along the coast did take place in accordance with the economic and social development plan of the municipal district, which had three priorities: 1) urban and infrastructure development, 2) the support of local investment, commerce, and tourism, and 3) the management and development of natural resources and the environment [11]. It is noteworthy that community density, represented by the urban area and building area (yellow area), has increased continuously since 2004.

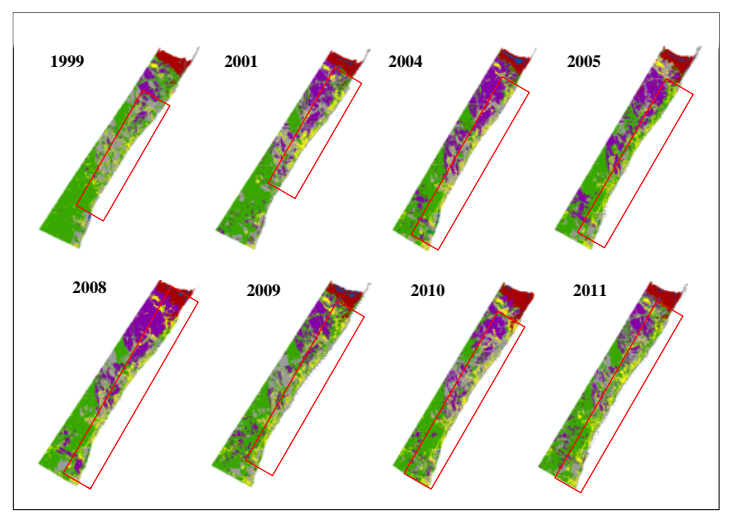

Fig. 6. Community density (yellow area) along the coast of Chao Samran during 1999-2011 has increased continuously since 2004.

Trends in land use change were also confirmed by interviewing key informants along the Chao Samran beach. They offered demographic data that offered further evidence of the expansion of communities in Chao Samran beach, as well as qualitative information on the satisfaction level of inhabitants. We followed the guidelines in Yamane [18] and gathered a population sample at a $90 \%$ confidence interval. We interviewed 100 persons of varying gender, age, domiciles, occupations, religions, levels of education and income. Extrapolating from the sample group, we can say that $60 \%$ of population who originally lived in Petchaburi remain in the region, while $40 \%$ population reside elsewhere. The main occupations are 1) entrepreneur, 2) agriculture, 3) government official, and 4) other. While $80 \%$ of the population owns its property, the remaining $20 \%$ rent.

\section{Impact of Coastal Zone Change on Erosion and Accretion Area}

Fig. 7 shows that severe erosion occurred in 2005-2006 and 2009-2010. In 2005-2006, incidences of erosion increased in the aquaculture area and urban and building area but decreased in the areas of bare land and agriculture. However, in 2009-2010, the rate of erosion increased in agricultural and bare land as well as in the urban areas, while aquaculture areas experienced a decrease. The highest accretion levels were in 2004-2005 and were related to the expansion of aquaculture, urban and building, and agriculture areas and a decrease in the area of bare land. In 2008-2009, accretion levels were related to increases in agriculture, bare land, and urban and building areas and to decreases in area for aquaculture. Fig. 8 shows the erosion and accretion rates for the whole beach as follows: low accretion (green), moderate accretion (light blue), and moderate erosion (yellow). The southern part experienced severe erosion (red).

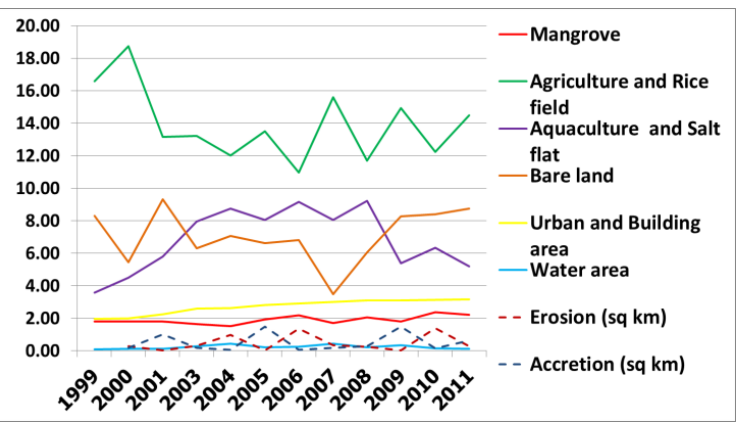

Fig. 7. Changes in erosion and accretion areas with land usage from 1999 to 2011. 


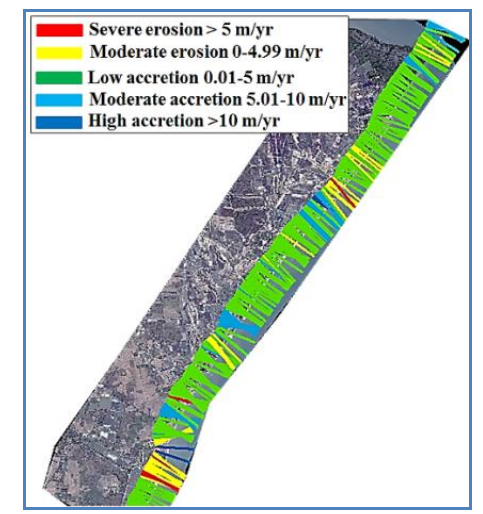

Fig. 8. Erosion and accretion rate from 1999 to 2011.

\section{Assessment of Economic Loss}

We also evaluated the risk of economic loss by analysing images of the threatened lands taken by the LANDSAT satellite in 1999-2011, by calculating the size of the precarious buildings and structures represented in the THAICHOTE images from 2012, and by interviewing key informants in the area for determining the threatened properties. The calculations indicate that the total value of the threatened land equals 168 million baht and the value of threatened buildings and structures amounted to 8 million baht, as shown in Fig. 9.
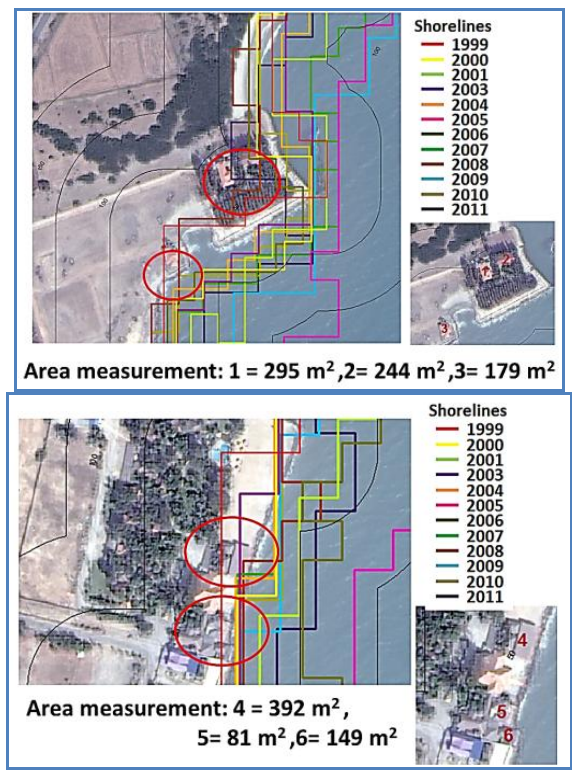

Fig. 9. Some buildings and structures threatened by shoreline retreat are shown in red circle. Base map is THAICHOTE in 2012 from GISTDA.

\section{CONCLUSION}

Chao Samran beach, located in Petchaburi Province, has a total area of 19,445 square kilometres and consists of seven villages with an approximate population of 4,500. The inhabitants work in five sectors: 1) agriculture and aquaculture (farming and fishing), 2) industrial, 3) commercial, 4) services, and 5) tourism cited in [14]. Data from the Petchaburi Provincial Statistical Office [10] show that total income of the Hat Chao Samran municipal district was 36.6 million baht, which represents a per capita income of approximately 20,824 baht. Agriculture is the main source of revenue: rice farming accounts for $59.29 \%$ of the total income generated, followed by tourism which accounted for $36.6 \%$.
In order to improve the quality of life of residents, the Hat Chao Samran municipal district implemented a 5-year economic and social development plan during 2007-2011 [11] to meet three priorities: 1) urban and infrastructure development, 2) the support of investment, commerce, and tourism, and 3) the management and development of natural resources and the environment. There are several existing plans to develop the land utilities of this coastal area. The coastal zone changes related to land use types at Chao Samran beach were analysed using images captured by the LANDSAT satellite in 1999-2011, THAICHOTE satellite in 2009-2012, and Quickbird satellite in 2009. Land usage at Chao Samran falls into five categories: 1) mangroves, 2) aquaculture and salt flats, 3) agriculture and rice fields, 4) bare land, and 5) urban and building area. The changes in land use increased significantly from 1999 to 2011, especially in the urban, aquaculture, and salt flat areas. On the other hand, we observed that the area of mangrove forest, water, and bare land experienced very little or no change. Only agriculture and rice field area decreased during this period. We noticed that some areas commonly used for agriculture and rice farming changed into areas for aquaculture and salt flat, bare land, and urban and building.

Considering that the distribution of communities along the coast has increased continuously since 2004 and that land utilization has changed gradually from agriculture to tourism infrastructure, this study found that erosion and accretion occurred in the coastal zone over two periods, specifically in 2005-2006 and 2009-2010. In 2005-2006, erosion led to an increase in aquaculture and urban and building areas but to decreases in bare land and agriculture areas. Meanwhile, in 2009-2010, it coincided with increases agriculture, bare land, and urban areas, while the area for aquaculture decreased. The accretion levels reached their highest point in 2004-2005 because of an increase in the aquaculture, urban and building, and agriculture areas. However, the area for bare land decreased during that time period. In 2008-2009, accretion levels coincided with increases in agriculture, bare land, and urban areas but with decreases in aquaculture area.

In addition, we also performed an assessment of the region's economic vulnerability. We considered both land threatened by erosion and accretion and buildings and structures affected by shoreline retreat in 1999-2011. The value of the damage was approximately 176 million baht. Accordingly, erosion and accretion had been increasing in the area. Thus, in 2007, the Hat Chao Samran commune began construction of a breakwater in the middle of the beach and this project was completed in 2009. This study found the erosion and accretion rates of the whole beach were as follows: low and moderate accretion rate $(0.01-10 \mathrm{~m} / \mathrm{yr})$ and moderate erosion rate $(0-4.99 \mathrm{~m} / \mathrm{yr})$, except in the southern part which experienced severe erosion rate $(>5 \mathrm{~m} / \mathrm{yr})$ and had no protection measure. This indicated that coastal development in the area, especially close to the beach, induced erosion and accretion both in the area and adjacent areas.

We also studied land use change and physical structures under threat by interviewing key informants along the Chao Samran beach. The survey gave us demographic information on the population in Chao Samran beach: it consisted of $60 \%$ local and $40 \%$ non-local residents. Most of the non-local 
population works at either a grocery store, resort, or construction project. The local inhabitants are mostly engaged in rice farming and shrimp cultivation.

The purpose of this study is to present both the positive and negative aspects of coastal area development. We conclude that the sustainability of coastal zone development should take into account social, economic, and physical dimensions. Greater attention should be paid to the effects of development in adjacent areas as well. Furthermore, a development plan should consider the most recent data, synthesised from multiple sources, and should use modern analytical tools. It is hoped that this study will be a guide for the sustainable development of coastal areas in many developing countries.

\section{ACKNOWLEDGMENT}

The study was made possible by the contributions, encouragement, and support of many individuals. The authors wish to express their gratitude to the reviewers for their valuable and helpful comments, which have improved the quality of the paper. We would also like to thank Geo-Informatics and Space Technology Development Agency (GISTDA) for supplying all the necessary images and equipment.

\section{REFERENCES}

[1] Office of Natural Resources and Environment Policy and Planning, "Interview with the secretary-general of the office of natural resources and environment policy and planning," Thailand's Nature and Environment Journal, vol. 5, no. 11, 2009.

[2] Geo-Informatics and Space Technology Development Agency, GISTDA Report (Thailand): Satellite Appraisal for Coastal Erosion along the Coast of Thailand (Phase I), 2010.

[3] Department of Marine and Coastal Resources, "The analysis and simulation of sea level rise on coastal areas of the upper Gulf of Thailand," DMCR report (Thailand), 2012.

[4] Food and Agriculture Organization of the United Nations (FAO), "Coastal protection in the aftermath of the Indian Ocean tsunami: What role for forests and trees?" Protection from Coastal Erosion, ch. 4, 2007.

[5] Kleppel, "The land use coastal ecosystem study (LU-CES)," presented at the Environmental Policy Forum, 1998.

[6] D. G. Pearce, Tourism Today: A Geographic Analysis, Longman: New York, 1995, pp. 35-38.

[7] K. Fedra and E. Feoli, GIS Technology and Spatial Analysis in Coastal Zone Management, 3rd ed., 1998, pp. 171-179.

[8] European Commission, Living with Coastal Erosion in Europe: Sediment and Space for Sustainability, June 30 2004, pp. 164-165.

[9] J. S. Allen et al., A GIS-Based Analysis and Prediction of Land Use Change in a Coastal Tourism Destination Area.

[10] Petchaburi Provincial Statistical Office. (2013). Statistical Information. [Online]. Availabel: http://www.hadchaosamran.com

[11] Hat Chao Samran Municipal District, "Three years development plan (2013-2018)," Report (Thailand), 2012.

[12] R. Li et al., "Digital tide-coordinated shoreline," J Mar Geod., vol. 25, pp. 27-36, 2002.

[13] E. A. Himmelstoss, DSAS 4.0 Installation Instruction and User Guide, 2009, p. 79

[14] J. K. E. Bayani, "Economic vulnerability and possible adaptation to coastal erosion in San Fernando City, Philippines," College of Economics and Management, University of the Philippines Los Banos, Philippines, 2007.

[15] Homeland4sale. (2014). Maketable price. [Online]. Available: http://phetchaburi.homeland4sale.com/

[16] Teedin108. (2014). Marketable price. [Online]. Available: http://www.teedin108.com/land/view/361370/

[17] Treasury Department. (2014). Land appraisal. [Online]. Available: http://property.treasury.go.th/pvmwebsite/

[18] T. Yamane, Statistics: An Introductory Analysis, 2nd ed., New York: Harper and Row, 1967.

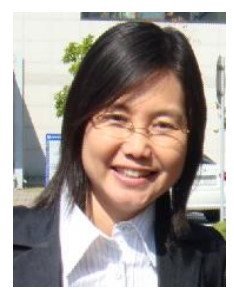

Siriluk Prukpitikul was born on November 13, 1968, in Suratthani province, Thailand. She got the M.Sc. in marine biology from the Norwegian University of Science and Technology (NTNU), Trondheim, Norway in 1998. Currently, she is working for geo-informatics and space technology development agency (public organization). She is the chief of natural resources division. Her expertise is about marine remote sensing (RS) and geographical information system (GIS). She published some researches. 